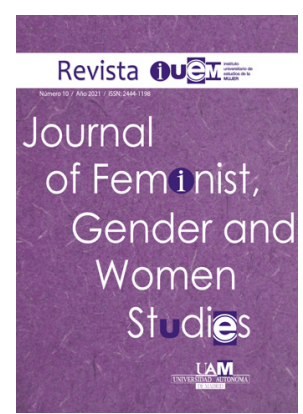

Recibido: 09/09/2019

Aceptado: 30/10/2020

\section{Visiones de la educación femenina en España (siglos XVI y XVII): Luis de León, Juan Luis Vives y Joseph Rojo}

\author{
Outlooks of female education in Spain (16 $6^{\text {th }}$ and $17^{\text {th }}$ centuries): Luis de León, Juan \\ Luis Vives and Joseph Rojo
}

Sergio Montalvo Mareca ${ }^{1, @ ~}$

${ }^{1}$ Universidad Complutense de Madrid-Instituto Universitario Menéndez Pidal

@ Autor/a de correspondencia: sergmont@ucm.es

\title{
Resumen
}

El presente trabajo analiza los diferentes puntos de vista en torno a la cuestión de la instrucción y la educación femeninas en los siglos XVI y XVII en España. Para lograr esta meta, se acude al análisis de tres testimonios, dos de ellos fundamentales para los estudios sobre la materia: la Instrucción de la mujer cristiana de Juan Luis Vives y La perfecta casada de Luis de León. Además, sendos testimonios se comparan con el Espejo de ilustres y perfectas señoras de Joseph Rojo. Esta obra data, aproximadamente, de las últimas décadas del siglo XVII. Tras haber trabajado con las ideas que cada autor refleja en su texto, véase infancia, formación intelectual, importancia de la virginidad o el ejercicio de las tareas domésticas, es posible obtener como conclusión una línea de pensamiento que parte de la misoginia medieval y continúa avanzando conforme se gestan y aclimatan los cambios de los siglos posteriores. El primer elemento de esta representación es La perfecta casada, pues, aunque se escribe después de la Instrucción de la mujer cristiana, los valores que refleja presentan mayor proximidad con los planteamientos medievales. El texto más avanzado es el de Rojo, más cercano a las nuevas ideas de la llustración. La obra permite comprobar si los cambios estudiados generaron una verdadera evolución en el pensamiento colectivo o si, por el contrario, no lograron modificar la conducta de los habitantes de la España del Siglo de Oro.

Palabras clave: Educación femenina, mujeres, Renacimiento, Barroco.

\begin{abstract}
This paper analyses the different points of view on the question of female instruction and education in the 16 th and 17 th centuries in Spain. To achieve this objective, we will analyze three testimonies, two of them fundamental for studies on the subject: Instruction of a Christian woman by Juan Luis Vives and The Perfect Wife by Luis de León. In addition, these two testimonies will be compared with the Mirror of illustrious and perfect women of Joseph Rojo. This work was written in the last decades of the 17th century approximately. After studying the ideas that each author shows in his text: for example on childhood, intellectual formation, the importance of virginity or domestic tasks, it is possible to obtain a conclusion in a synthesized ideological way. On this idea, we will draw a line of thought that will reflect the progressive gestation of the changes in the misogynist mentality of the Middle Ages. The first element of this line is The Perfect Wife. Although it is written after Instruction of a Christian woman, it presents values closer to medieval discourses. On the contrary, Rojo's text is the most advanced and its conceptions are similar to the new views of the Age of Enlightenment. His work allows us to verify whether the changes studied generated a real evolution in collective thought or whether, on the contrary, they could not affect the behavior of the people of Spain in the Golden Age.
\end{abstract}

Keywords: Female education, women, Renaissance, Baroque. 


\section{INTRODUCCIÓN}

El interés por el saber que caracterizó el Humanismo y el Renacimiento también posibilitó la revisión de todos aquellos conocimientos, ideologías y doctrinas que habían llegado por herencia desde los tiempos pasados. De esta manera, los diferentes pensadores, escritores, teólogos y tratadistas abordaron cuestiones polémicas como la legitimidad del poder, determinados aspectos del cristianismo o la reforma de los métodos de educación, todo ello desde nuevas perspectivas. En cuanto a este último apartado, estaba estipulado que la enseñanza de los varones debía comprender varias disciplinas: religión, letras, habilidades militares, historia o ciencias, entre otras materias. La realidad de las mujeres, en cambio, era muy diferente.

La sociedad renacentista y barroca mantenía la noción aristotélico-cristiana (las bases de este análisis y de todos los que siguieron se encuentran en Horowitz, 1976), que señalaba a la mujer como un ser biológicamente inferior al varón, más débil y, por tanto, físicamente ineficiente. Asimismo, se señalaba que la inteligencia de ellas era inferior a la del sexo opuesto, por lo que cualquier tipo de formación estrictamente académica resultaría infructuosa. Por lo tanto, resulta de suma importancia entender el término 'educación', aplicado a las mujeres de estos siglos, en su acepción más amplia, evitando caer en la concepción académica del vocablo. Dice la Real Academia en su definición: «Desarrollar o perfeccionar las facultades intelectuales y morales del niño o del joven por medio de preceptos, ejercicios, ejemplos, etc». De acuerdo con el argumento anterior, los tratados de educación femenina abogaban por la dedicación al hogar, el cuidado de los hijos, pues de su nacimiento y buena crianza dependía, en gran parte, el honor de su familia; además del mantenimiento de las buenas costumbres y un estricto ejercicio de la espiritualidad.

Uno de los primeros testimonios peninsulares en acercarse a estas nociones fue el Libre de les dones de Francesc de Eiximenis, obispo de Barcelona (remito a la edición de Clausell Nácher, 2007). Obra escrita en catalán y cuya fecha aún está sin determinar con exactitud, aunque parece próxima a la última década del siglo XIV. Se trata de un caso especial, pues aborda el tema desde el elogio y no desde la denuncia del error; es más, el obispo de Barcelona escribe en su obra contra aquellos moralistas que dirigen maldades contra el sexo opuesto. De la segunda mitad del siglo XV (ca. 1468-1469) data otro testimonio con la misma temática y también escrito por un religioso: Martín de Córdoba, un fraile de la Orden de San Agustín. Su obra, el Jardín de nobles doncellas (me baso en la edición de García, 1956) presenta la forma propia de los textos humanistas, pues propone una serie de máximas que deben cumplir las mujeres para ser honradas. Como también sucederá con Juan Luis vives, Martín de Córdoba persigue una doble finalidad. Por un lado, busca instruir a las doncellas para que sean virtuosas, y, por otro, honrar a una figura relevante, en este caso, a una joven Isabel la Católica, entonces todavía aspirante a la Corona de Castilla. De esta manera, el religioso pretende aportar toda una serie de pautas para la crianza de la futura monarca que garantizarían su éxito en el gobierno del reino.

Tras el auge renacentista de textos que se ocupaban de esta materia, entre los que destacan dos de los protagonistas de la siguiente comparación: La perfecta casada y la Instrucción de la mujer cristiana, el interés se mantuvo, aunque con menor intensidad. Conforme avanzó el XVII, la literatura enfocada en la formación del sexo femenino experimentó una progresiva desaceleración que respondía al progresivo debilitamiento de la mentalidad barroca en España. En cambio, la llegada de las nuevas ideas venidas de la Francia ilustrada logró abrir un nuevo cauce en la literatura moral femenina. En esos momentos, el pensamiento social avanzaba ya hacia la reivindicación de la autonomía y la libertad de las señoras, desafiando así el orden heredado y sostenido, en gran parte, durante el Renacimiento (Ortega López, 1988).

\section{VISIONES DE LA EDUCACIÓN DE LAS MUJERES EN LOS SIGLOS XVI Y XVII: TESTIMONIOS ESCOGIDOS PARA LA COMPARACIÓN}

Los textos del siglo XVI y XVII que aluden a la educación de las mujeres son numerosos y muchos coinciden en los parámetros que recomiendan o censuran. A continuación, recojo tres de ellos y los comparo con el fin de lograr puntos en común, pero también de advertir sobre sus diferencias más esenciales. Los tres textos son La perfecta casada de Luis de León, la Instrucción de la mujer cristiana de Juan Luis Vives y el Espejo de ilustres y perfectas señoras de Joseph Rojo. He seleccionado los dos primeros puesto que son dos de los testimonios más famosos y conocidos que versan sobre la formación de las mujeres. En cambio, he optado por el texto de Rojo, hasta hoy inédito, para dar a conocer un testimonio poco conocido cuya fecha, circa 1670 , permea nuevas perspectivas en lo relacionado con el sexo femenino y su comportamiento, tanto correcto como incorrecto.

Si bien es cierto que La perfecta casada (me serviré de la edición realizada por San José Lera, 2002) es posterior a la obra de Vives -la prínceps data de 1583-, desde el punto de vista ideológico resulta más conservadora, por ello tomo este testimonio como el más estricto de los tres. La formación religiosa de Luis de León hace de La perfecta casada una "obra bíblica» como señala el editor (San José Lera, 2002: 12-19), de ahí que la postura del catedrático salmantino esté tan marcada: "la perspectiva desde la que se aborda depende, en gran medida, de la postura ortodoxa de los Padres de la Iglesia frente al problema del matrimonio, y más específicamente, frente a la mujer, vista con acritud desde el propio texto bíblico» (Ibid., 20). Luis de León escribe su obra apoyándose en el capítulo XXXI del Libro de los Proverbios de Salomón, de modo que La perfecta casada es, en realidad, una recopilación de comentarios, ciertamente libres, que el religioso elabora a partir de cada uno de los proverbios. A través de estas glosas, Luis de León explica las cualidades que deben tener las señoras para desarrollar con profesionalidad el oficio de esposas, pues lo considera una actividad profesional más (Martí, 2004: 378). Esta concepción del matrimonio como negocio requiere un desarrollo desde el punto de vista económico y no solo moral. El interés de Luis de León por la gestión femenina de la hacienda ha motivado la aparición de investigaciones que separan este texto del corpus de tratados educativos, pues consideran que en él no impera tanto el valor moralizante como el interés 
socioeconómico (Ibid.: 379).

Por su parte, Juan Luis Vives fue una de las principales figuras del Humanismo español, a pesar de que, aunque nació en Valencia, apenas residió en España tres lustros. Sus escritos gozaron de gran popularidad dentro y fuera de la Península. Su tratado De institutione foeminae christianae (traducido más tarde por Juan Justiniano con el título de Instrucción de la mujer cristiana, a cuya versión remito a través de la edición de Howe, 1995), presenta una división en tres libros en la que cada uno corresponde a un estado de la mujer, entiéndase: soltera, casada y viuda. La Instrucción de la mujer cristiana bebe también de la tradición bíblica, así como de los escritos de los padres de la Iglesia, especialmente de los de San Jerónimo, al igual que sucedía en La perfecta casada. Sin embargo, las fuentes de Vives superan las del teólogo tanto en número como en diversidad (Moreno Gallego, 2006: 392-393). El tratado no logró el beneplácito de Erasmo de Rotterdam, quien lo consideró excesivamente castigador contra las mujeres (Martín Casares, 2002: 227). Erasmo no erró en su juicio, es evidente, pues, aunque supone un cierto progreso respecto a La perfecta casada, la obra de Vives continúa comulgando con la concepción cristiana-aristotélica de la mujer como un ser inferior y proclive a la caída (Monsegú, 1961: 339).

La última de las obras de esta comparación es, como señalaba antes, un texto inédito. Se trata de un diálogo, dividido a su vez en otros ocho, en los que los interlocutores, un padre -don Enrique- y su hija -doña Blanca-, charlan sobre los comportamientos propios de una mujer ejemplar en determinados momentos fundamentales para la vida de ella, por ejemplo, cuando alcanza la edad adecuada para ser casada, en los días anteriores y posteriores al enlace, y cuando enviuda. Frente a dos obras canónicas como son La perfecta casada y la Instrucción de la mujer cristiana, el interés del diálogo de Joseph Rojo es su naturaleza casi ignota y las características textuales de su manuscrito (Montalvo Mareca, 2019).

El Espejo de ilustres y perfectas señoras de Rojo presenta numerosas coincidencias con la Instrucción de la mujer cristiana. Una de ellas es el recurso de la estructura tripartita que ya mencioné antes. En el caso de Rojo, la división se ordena por diálogos: los dos primeros pertenecen al periodo en el que doña Blanca es doncella; los cuatro siguientes, a la etapa en la que ya está casada y, por último, los diálogos séptimo y octavo transcurren durante su viudedad. Coinciden, en este caso los tres testimonios, en el recurso retórico de los exempla para ilustrar aquellos comportamientos, tanto positivos como negativos, a los que aluden en sus textos. Esta tendencia es especialmente acusada e interesante en el texto de Vives, por lo que remito al excelente estudio que hace de ello Muguruza Roca (2010). De hecho, la nómina de mujeres célebres o malvadas que eligen ambos autores coincide a la letra en no pocos momentos, lo que permea la hipótesis de que Rojo conociese bien la obra del tratadista valenciano, si no es que los dos se sirvieron de las mismas fuentes secundarias, polianteas y centones, para la redacción.

\section{SIMILITUDES Y DIFERENCIAS EN LA CONCEPCIÓN DE LA MUJER MODÉLICA SEGÚN LUIS DE LEÓN, JUAN LUIS VIVES Y JOSEPH ROJO}

\section{Infancia de la criatura}

La educación de la niña desde su nacimiento es una de las primeras cuestiones que aborda el humanista valenciano, pues, como advierte, esta puede evitar mayores cuidados en el futuro. También escribe sobre la lactancia materna y sus beneficios como vía de transmisión directa de las aptitudes de su progenitora:

«Marco Fabio Quintiliano tomando a criar y doctrinar al orador quiere que se comience desde la cuna, teniendo por bien que ningún tiempo se pierda pudiendo emplearse en su crianza e instrucción. Pues icuánto mayor cuidado debemos poner en la crianza y vida de la mujer cristiana; siendo tan importante al vivir humano, que todo el bien y el mal que en el mundo se hace se puede sin yerro decir ser por causa de las mujeres según el proceso de esta obra se podrá comprehender! Débese, pues, nacida la niña, entender cómo se crie, y comenzando desde la leche, yo querría mucho que se la diese su madre si posible fuese, lo mismo aconsejaron Plutarco, Favonio, y otros grandes filósofos. La razón de esto parece principalmente ser porque habrá más amor y caridad entre madre e hija si no se partiere por medio el nombre de la madre y a darlo el ama que la criare, a quien los niños también suelen llamar madre. También, porque en cierta manera la madre tendrá a la hija por más verdaderamente suya habiéndola no sólo traído en su vientre y parido, más aún desde niña la tuvo casi de continuo en sus brazos, le dio su leche, la crió de su sangre y la arrulló en su seno... " (Vives: 37).

Esta visión de la leche era un pensamiento muy asentado aún en el siglo XVI, como señala Nausia Pimoulier (2013: 31-40), y con el que comulgaban la mayor parte de los teóricos y moralistas. Luis de León también defiende que lo natural es que la progenitora amamante a su criatura. Con este razonamiento expresa, además, su frontal rechazo a que la alimentación de las criaturas recayese en las nodrizas, algo que era una práctica habitual:

"Lo que sigue después del parto es puro oficio de la madre, y lo que puede hazer bueno al hijo y lo que de veras le obliga. Por lo qual, téngase por dicho esta perfecta casada que no lo será si no cría a sus hijos, y que la obligación que tiene por su oficio a hazerlos buenos, esa misma le pone necesidad a que los críe a sus pechos; porque con la leche, no digo que se aprende, que eso fuera mejor, porque contra lo mal aprendido es remedio el olvido; sino digo que se beve $y$ convierte en substancia y como en naturaleza, todo lo bueno y lo malo que ay en aquella de quien se recibe. Porque el cuerpo ternezico de un niño, y que salió como començado del vientre, la teta le acaba de hazer y formar. Y según quedare bien formado el cuerpo, así le avendrá el alma después, cuyas costumbres ordinariamente nascen de sus inclinaciones dél» (León: 186-187).

La misma concepción aparece en el Espejo de ilustres y perfectas señoras. Mientras que Juan Luis Vives presenta la acción de dar el pecho como una obligación para la madre, Rojo suaviza el tono y se limita a aconsejar esta práctica, pues encuentra en ella diferentes beneficios: 
"Para todo importa mucho también la noble sangre en las mugeres porque será así más cierta la educación en las buenas costumbres, virtudes que no solo importan al respeto suyo, sino que generosamente se derivan a los descendientes. Las leyes aconsejan que elijan las mugeres de nobles padres y de buena enseñança porque, aunque a la naturaleza de cada uno dio Dios su libre albedrío, muchas cosas naçen con el ánimo que se trasfieren en los hijos, porque como el cuerpo y el alma tienen entre sí una proporción que haze conforme armonía, se colige que de la buena templança han de naçer efectos semejantes, porque como fuere el campo, tal será la cosecha; cual el obrero, tal la obra; y cual el labrador, tal la cultura. Bien que por acçidentes ocultos suele pervertirse esta orden de la naturaleza. Mas, al fin, esto es lo más cierto, pues como dize un poeta: los fuertes naçen de los fuertes; y el novillo y el potro muestran la virtud del padre y las águilas no sacan hijos débiles». (Rojo: 17v-18r).

Otra de las primeras medidas exigidas por Vives es la separación de las niñas respecto de los varones desde los primeros años, incluso aunque estos sean sus propios hermanos. Con ello se pretende evitar que se establezcan vínculos fuertes que hagan que la niña se acerque al sexo masculino temprana y peligrosamente. El valenciano no solo se refiere a todo lo relacionado con el deseo sexual, sino también a la aparición de un fuerte anhelo de la ociosidad y el divertimiento del que disfrutan los hombres desde pequeños, que se opone a la austeridad y el recogimiento que se muestra a las niñas:

"Luego que la niña será destetada y comenzará a hablar y andar, todos sus pasatiempos sean con otras muchachas de su igual, y esto en presencia de su madre o ama o alguna honrada dueña anciana, la cual temple aquellos juegos y los encamine a cosa de virtud, no entrevenga plática de hijos varones, ni se avece la muchacha jugar, ni tomar algún pasatiempo con los muchachos, porque está averiguado que naturalmente amamos mucho aquéllos con quien desde niños conversamos y jugamos. Este amor puede más en la mujer porque ella naturalmente es más inclinada a cosas de placer que no el varón. Así que en aquella edad que no se conoce bien ni mal no se le avece cosa malan (Vives: 41).

En consonancia con esta idea, Vives señala otras distracciones sanas para las jóvenes que, además, les brindarán una infancia sana y provechosa para su futuro casi ineludible: el matrimonio. De entre todas las que señala el humanista valenciano, la más noble es el arte de hilar:

«Destruye el regalo a los hijos (en esto no hay duda), pero a las hijas no las destruye, sino que las echa a perder a remate. Aprenderá, pues, la muchacha juntamente letras, hilar y labrar, que son ejercicios muy honestos (que nos quedaron de aquel siglo dorado de nuestros antepasados) y muy útiles a la conservación de la hacienda y la honestidad, que debe ser el principal cuidado de las mujeres» (Vives: 4344).

"La reina doña Isabel mujer del Rey Católico don Fernando, quiso que todas cuatro sus hijas (de las cuales, las dos fueron reinas de Portugal, la tercera vemos en España madre del Emperador Carlos rey nuestro, la cuarta mujer de Enrique octavo, rey de Inglaterra) quiso (digo) que todas cuatro supiesen hilar, coser y labrar» (Vives: 46).

Igualmente, importantes son las labores de costura e hilado para Luis de León, quien también alude a Isabel la Católica para reforzar sus pareceres, aunque va más allá. El religioso aprovecha el ejemplo de la monarca castellana para criticar el estado nobiliario, donde se concebía como un desprestigio que las mujeres de alta cuna hilasen. De acuerdo con esta concepción, solo tejían aquellas señoras que procedían del estamento más bajo: sirvientas, campesinas, etcétera:

«Pero ¿qué es menester traer exemplos tan pasados y antiguos, y poner delante los ojos lo que, de muy apartado, quasi se pierde de vista? Sin salir de nuestras casas, dentro de España, y casi en la edad de nuestros abuelos, hallamos claros exemplos de esta virtud, [como de la Reyna Cathólica doña Isabel, princesa bienaventurada, se lee]. Y si las que tienen agora por tales y se llaman duquesas y reynas no se persuaden bien por razón, hagan experiencia dello por algún breve tiempo, y tomen la rueca, y armen los dedos con la aguja y dedal» (León: 110-111).

\section{Educación intelectual}

Los tres autores se pronuncian al respecto de la educación en letras para las mujeres. Luis de León concede un tratamiento especialmente somero a esta cuestión, pues considera que las esposas deben centrarse en la gestión doméstica y evitar otras distracciones, como la lectura o la escritura, campos que concede exclusivamente a los hombres. Reservo, pues, los fragmentos de La perfecta casada para el siguiente apartado con el fin de no repetirlos.

Por su parte, el humanista valenciano, en cambio, defiende el acceso femenino al conocimiento, aunque establece tantas restricciones que cuesta descifrar si verdaderamente lo considera provechoso. Según el pensamiento vivista, que las jóvenes tengan la habilidad de leer puede darles acceso a malas fuentes que podrían poner en riesgo su espiritualidad (tomo el siguiente fragmento, aunque lo amplío, de Montalvo Mareca, 2018: 54):

"Cuando le enseñan a leer, sea en buenos libros de virtud, porque toda agua no es de beber. Cuando le mostraren escribir, no le den materia ociosa o vana sino alguna cosa sacada de la sagrada escritura o alguna sentencia de castidad tomada de los preceptos de la filosofía, la cual escribiéndola una y muchas veces se imprima firmemente en la memoria. No pierda el maestro ni la madre cuidado de tenerla de continuo debajo de las alas de doctrina y crianza si no quieren que el ingenio de la muchacha se torne huero y en lugar de pollo saquen duelo. Porque todas las cosas del mundo cuando dejan de ir no se mueven; el caminante cuando no camina no va adelante. La nave mientras no navega estando en lo alto no se llega a puerto, pero el ingenio mientras no aprovecha en la virtud, no sólo deja de ganar tierra en el bien, mas aún la pierde tornando en el mal. Y mucho más caen los muchachos que los grandes y más las mujeres que los hombres y aún por esto dijo aquel sabio poeta Horacio en su Arte poética que el barro mientras es fresco se debe labrar y no dar reposo a la rueda para hacer el vaso, y lo que comunmente se dice el hierro mientras está caliente debe ser batido» (Vives: 56-57).

Rojo es quien muestra mayor apoyo hacia la figura de la mujer estudiosa y sabia; tanto, que su defensa ocupa la mitad del primer diálogo y vuelve a aparecer repetidas veces en los siguientes. El primer argumento que emplea 
es una crítica frontal a quienes se oponen a que las mujeres reciban una formación académica al uso puesto que las consideran intelectualmente suspensas. El personaje de don Enrique propone que esa opinión responde al miedo masculino a que las mujeres accedan a determinados sectores tradicionalmente vedados para ellas. Por eso presenta una extensa nómina de mujeres que destacaron por su inteligencia y destreza para las ciencias y artes.

"A este he dirigido el dulçe trabajo a que os he obligado con el estudio de algunas çiençias, logrado con tanto honor vuestro y tanto contento mío sin que este ilustre ornato a tantas partes os haya desvaneçido ni estragado la suave modestia de vuestra condiçión. Peligro que, reçelado ásperamente de tantos, los ha obligado a condenar y aún prohibir los estudios a las mugeres injustamente, pues también mereçen ellas alabança por la sabiduría. Y muchas hubo en la edad pasada, y aún en la presente, que en diferentes çiençias florecieron porque, como el ingenio es una potençia y fuerça natural o aprehençión nativa por la cual nos disponemos a las operaciones y a las notiçias peregrinas de todas las cosas, el temperamento de algunas mugeres debe de haber sido acomodado a esta fáçil aprehençión y aún con más subtileza que la de los hombres. Mugeres ha habido tan esercitadas o tan inclinadas por propia virtud del ánimo, que se llama más propiamente habilidad natural, que han açertado aún a lo escondido de muchas razones de la filosofía sin tener la guía de ningún maestro en muchas no fáçiles inteligencias de lo más culto de la naturaleça. Aquí se conoçe la falta de notiçia o la sobra de inorançia de los que condenan el ingenio de las mugeres por inútiles a tanta açción como el discurrir en una o más numerosas donde han de juntarse conocimiento de algunas çiençias y artes, elecçión y prudencia para la disposiçión de todo» (Rojo: 11v-13).

Don Enrique cierra su discurso diciendo que los realmente ignorantes son aquellos varones que no conocen o tratan de no recordar aquellos casos en los que fue una mujer la que arrojó luz sobre algún "aspecto oscuro» del conocimiento. Presenta a continuación otra extensa línea de estos casos, como sucedió con Aspasia de Mileto, a quien cita después, filósofa de la que Sócrates admitió tomar varios de sus postulados. Los ejemplos abarcan sabias desde la Grecia antigua hasta la segunda mitad del siglo XVI, como el de Vittoria Colonna, marquesa de Pescara:

«Safo inventó los versos, Pola Argentaria emendó a Lucano, su marido, los tres primeros libros de su divina Farsalia; Aspasia fue de tanta dotrina, que, confiesa Sócrates, doctísimo filósofo, aprendió de ella grandes secretos de la filosofía; Cleobulina, hija de uno de los siete sabios de Grecia, escribió enigmas ingeniosísimas en versos hexámetros; Hortensia, hija de Sortensio, orador famoso, le igualó, muerto él, en la elocuençia y en el uso de los negoçios. Gispatia escribió doctos libros de astronomía, Hildegarda, virgen germana, escribió sobre la sagrada regla de sant Benito y respondió altamente a treinta teólogas cuestiones que la propusieron. $Y$, en nuestros tiempos, la esclarecida virgen Santa Teresa de Jesús, divino honor de nuestra España, en heroica santidad la enriqueçió de soberanos tesoros con sus escritos, ilustrado del espíritu santo el más generoso natural y más claro ingenio que fue crédito de su sexo. En este mismo siglo, la ilustre y docta marquesa de Pescara fue luz de Italia y exemplo de nobles mugeres» (Rojo: 13v-14v).
Tanto Vives como Rojo recurren en sus textos a un antiguo recurso retórico muy en boga durante el Renacimiento: el exemplum virtutis. Con él muestran mujeres que guiaron su vida de forma virtuosa y que tuvieron gran fama en su tiempo o, por el contrario, enseñan las consecuencias que acarreará para la mujer un mal comportamiento (Breitenstein, 2018). La estrecha relación que existe tanto en la disposición técnica de los ejemplos, como en el contenido de estos, deja entrever que Rojo sí tuvo en consideración la obra de Vives en el momento de la redacción del Espejo de ilustres y perfectas señoras, pues reproduce, aunque con sutiles cambios, algunos pasajes del De institutione. Toma, por ejemplo, la organización de los ejemplos femeninos por categorías: "Hasta treinta ejemplos femeninos utiliza el humanista para aleccionar a las esposas del comportamiento que han de tener con sus maridos (II, 4); quince para la exaltación del lanificio (I, 3); once para mostrar el pudor femenino en el lecho matrimonial $(I I, 6)$ y así sucesivamente» (Muguruza Roca, 2010: 684). Si el humanista se refiere a Safo, Leoncia, Sempronia, Cornelia, Cleobulina, Casandra, Pitia, Fenionoe, Sulpicia, Corina, Hortensia y Pola Argentaria, por citar solo algunas de las primeras mujeres que aparecen, el autor del Espejo... escribirá también sobre la mitad de este listado de mujeres ilustres de la Antigüedad.

\section{Economía doméstica}

Como ha quedado reflejado en el epígrafe segundo, uno de los aspectos de La perfecta casada en los que más ha profundizado la crítica literaria ha sido en la preocupación por la economía doméstica. Aunque Luis de León es quien analiza con mayor profundidad esta tarea reservada a las esposas, los otros dos autores también consideran conveniente instruir a la mujer para que sea buena administradora y sepa gestionar los bienes de la familia. Para el religioso de Belmonte, poseer una esposa ducha en la gerencia doméstica es una garantía para el marido, quien podrá mantener el hogar con su trabajo sin necesidad de procurar ingresos extra, por ejemplo, luchando en alguna batalla:

«Pues dize ahora el Spíritu Sancto que la primera parte y la primera obra con que la muger casada se perficiona, es con hazer a su marido confiado y seguro que, teniéndola a ella, para tener su casa abastada y rica no tiene necesidad de correr la mar, ni de yr a la guerra, ni de dar sus dineros a logro, ni de enredarse en ratos viles e injustos, sino que, con labrar él sus heredades, cogiendo su fructo, y con tenerla a ella por guarda y por beneficiadora de lo cogido, tiene riqueza bastante» (León: 93).

Juan Luis Vives sigue su estela y, sirviéndose de Aristóteles nuevamente, apela a la inferioridad biológica de las mujeres, quienes son temerosas por naturaleza y gracias a ello conservan con mayor celo el dinero que aporta el marido. De este modo, el valenciano presenta dos conductas totalmente diferenciadas por sexos: la activa, que pertenece al marido, y la pasiva, que corresponde a la mujer. Los varones deben ser diligentes, pues de ello depende el capital que entre a sus casas. Por su parte, las señoras deben tener las cualidades opuestas: apocadas y cobardes, pues su objetivo ha de ser que el dinero no se malgaste ni falte. Volveré sobre esta noción en el epígrafe siguiente:

"Con la sobredicha templanza van trabajadas la 
mesura en el gastar y la diligencia de mirar por su hacienda honestamente (a la primera llaman los latinos Parsimonia, y a la segunda Frugalidad), las cuales dos virtudes, Platón y Aristóteles quieren que la mujer las tenga en la hacienda de su marido y en su casa. Comoquiera que el hombre debe ganar y la mujer guardar, y aún parece que a esta causa la naturaleza proveyó que el hombre tuviese ánimo y osadía y la mujer no tanto, porque él fuese para buscarlo y ella temiese de mal meterlo» (Vives: 125).

En cuanto al autor del Espejo de ilustres y perfectas señoras, parece desoír aquí la diferenciación biológica que antes sí aceptó, aquella "femenil flaqueza» que temen los padres de niñas. Considera que el gobierno del hogar debe descansar sobre la esposa, a quien recomienda que sea sensata y que no derroche el capital para equipararse a otros en los bienes materiales:

"La misma orden, tiniendo mucho cuidado de que vuestra casa no paresca grande en la desorden sino en la autoridad honesta y conveniente, sin consentir que vanamente en ella, por adelantarse a otros iguales, se gaste más de lo que sufrieren vuestras ventas; ni que escusados lucimientos empeñen vuestra casa, pues no hay más triste ni aún más afrentosa fortuna que neçesitar de muchos por no haberse contenido cuerdamente en los límites del caudal propio» (Rojo: 33-33v).

\section{Inferioridad femenina y preocupación por la virginidad}

La acusada preocupación de los tratadistas por la pureza del alma y el cuerpo de las mujeres radica, una vez más, en la concepción de la mujer como un ser biológicamente, pensamiento heredado de Aristóteles y, en gran parte, de la tradición cristiana del Génesis (Charlton, 1999: 104-105). Para Vives es necesario que las mujeres se encuentren a cargo de otro ser más perfecto, el hombre (De animalia, Lib. IX, 608a 22-25; nota tomada de Howe, 1995: 226), que es el encargado de guiarlas por el camino de la virtud, pues si ellas mismas se condujeran, terminarían en el pecado. Luis de León plantea una tesis similar a la del valenciano, pues manifiesta que la mujer es biológicamente más débil y, por ello, necesita de una instrucción ejemplar en su juventud, idea que ya he expuesto en los apartados anteriores. Esta formación, en caso de ser eficaz, hará florecer diferentes virtudes que perfeccionaran, según la mentalidad expuesta, a las mujeres para el papel que la sociedad les reserva: esposas, madres y administradoras del hogar:

"No sólo la usanza y costumbre de nuestros antepasados, mas aún todas las leyes divinas y humanas y la misma naturaleza da voces y manda expresamente que la mujer debe ser sujeta al marido, y que le debe obedecer. En todo linaje de animales las hembras son sujetas a los machos $y$, síguenlos, y haláganlos, y sufren ser castigadas de ellos, y naturaleza enseñó que esto es necesario hacerse, y que conviene que se haga. La cual (según dice Aristóteles en los libros de los animales) dio las hembras menos nervosidad que no a los machos, y hízoles que tuviesen las carnes más blandas, y el vello más delicado. Allende de esto, las cosas que les dio por armas, como son dientes, cuerpos, espuelas, y otras cosas tales dejó de darlas a muchas de las hembras habiéndolas dado a los machos, como son los ciervos y jabalís, cuyas hembras no tienen cuernos ni colmillos, a otras dio las mismas armas, pero no tan grandes como a los machos, lo cual se puede muy bien ver en las vacas, que aunque tengan cuernos, no los tienen tan grandes, ni tan robustos, como los toros. Con las cuales cosas todas nos mostró la maestra naturaleza que la defensa está en los varones, y que las hembras no son obligadas a más de obedecer y seguir a ellos, y estar debajo de su tutela y amparo con toda humildad, sujeción y mansedumbre» (Vives: 225-226).

"Porque, como la muger sea de su natural flaca y deleznable más que ningún otro animal, y de costumbre e ingenio una cosa quebradiza y melindrosa, y como la vida casada sea vida subjecta a muchos peligros, y donde se ofrescen cada día trabajos y dificultades muy grandes, y vida ocasionada a continuos desabrimientos y enojos, y como dize Sant Pablo, vida adonde anda el ánimo y el coraçón dividido y como enagenado de sí, acudiendo agora a los hijos, agora al marido, agora a la familia y hazienda, para que tanta flaqueza salga con victoria de contienda tan dificultosa y tan larga, menester es que la que ha de ser buena casada esté cerca de un escuadrón de virtudes, como son las virtudes que avemos dicho» (León: 86).

La opinión de Rojo es afín a la de los dos autores anteriores. En un determinado punto del diálogo primero, el padre, don Enrique, expresa que siente que su muerte está próxima y, por tanto, se preocupa por la continuidad de la buena fama de su casa. Sin embargo, tiene la certeza de que esta se mantendrá, e incluso, aumentará a pesar de que su única descendiente es una mujer. Además, don Enrique señala que su esposa y madre de doña Blanca, de nombre doña Elvira y fallecida desde el comienzo de la obra, fue un modelo de virtudes. Por tanto, y al haberse encargado ella de la educación de la hija, doña Blanca será, al menos, tan excelente como su madre. De ello deriva una de las nociones citadas al comienzo de este trabajo, la responsabilidad de las mujeres que son madres, pues a través de su descendencia deben de honrar a la familia de la que proceden:

"Partiré de esta vida sin los miedos que suele llevar quien dexa el honor de su casa a disposición de la femenil flaqueza, aun cuando no quedárades a la de tanta prudençia como venero en vuestra madre, cuya obediencia amorosa os encargo por primer preçeto» (Rojo: 7-7v).

Las preocupaciones se acentúan conforme las muchachas maduran y se aproximan a la adolescencia, pues si a través del correcto desempeño de la maternidad y del matrimonio son capaces de ensalzar su estirpe, también pueden condenarla si no cumplen con el respeto que deben a su cuerpo. Así, Vives habla de la virginidad (únicamente de la femenina) como el cénit de su pureza. Habla de «verdadera virginidad", que no es otra que la que combina la inocencia del cuerpo con la inocencia del alma. De eso se extrae la importancia de salvaguardar a las niñas mientras que son doncellas, pues el momento más fértil para que fijar en ellas los patrones de conducta antes expuestos:

"Ahora todas mis palabras serán dirigidas a la virgen, la cual tiene en sí el bien incomparable que es la integridad o puridad e incorrupción de pensamiento y del cuerpo donde cosiste la verdadera virginidad" (Vives: 69).

Para Rojo la virginidad femenina también es la condición más importante, no solo por las nociones de inocencia y pureza antes expuestas, sino además porque es el momento en el que las mujeres se encuentran más cerca 
de Dios, pues viven alejadas de la carne:

"Disputan algunos sagrados escritores si es más perfecto este estado que el de la casada o la viuda porque dizen que, aunque es mejor que los dos, ellos pueden ser más perfectos porque pueden exercitar más bien la virtud de la caridad; pero finalmente concluyen que la virginidad sea como reina; la viudez, como señora, y el estado matrimonial, como siervo; y que sola la virginal castidad es la que en este mortal tiempo representa algún retrato de la inmortalidad de la gloria, porque la virginal pureza se ordena a la vida contemplativa y el estado del matrimonio, a la activa» (Rojo: 20v-21).

A pesar de estos argumentos, el verdadero motivo que genera esta preocupación masculina guarda relación con la organización familiar y la fama del hogar que tanto preocupaba al personaje de don Enrique. La pérdida ilícita de la virginidad, solo de la femenina, suponía la deshonra para la mujer, nunca para el varón, pero también para todos los familiares de esta. Por tanto, los hombres se esforzaban en alejar a sus hijas y hermanas de cualquier riesgo que pudiese deslucir su propia reputación:

"Toda se le hará triste, lloroso, dolorido, lleno de espanto y rabia contra sí misma. ¿Qué dolor es el de los padres? ¿Qué infamia la de los parientes? ¿Qué tristeza de los amigos? ¿Qué gemidos de los familiares? ¿Qué lágrimas de los que te criaron? iO hija, estas alegrías das en pago de tantos cuidados! ide tantas malas noches! ide tantos trabajos y fatigas! ¿Es éste es el fruto de la crianza? ¿Este es premio y galardón de los beneficios? Considera, pues, triste, considera (no así ligeramente) las maldiciones, los reproches, los denuestos de los padres, de los familiares, de los amigos y vecinos blasfemando a tu maldad y la hora en que naciste, para poner infamia en casa de los tuyos, vergüenza en los que te criaron, mancilla en tu honra, dolor en tu vida, pena en tu alma» (Vives: 76).

Lo mismo ocurría en los casos de adulterio cuando la mujer estaba casada. Los maridos se esforzaban en procurar la castidad de sus esposas por medio de la clausura. Tanto Luis de León como Rojo recomiendan a la mujer que se guarde de dar paseos o de dejarse ver sola por la ciudad como método de prevención de la infidelidad. Además, muestran admiración grande por aquellas que se recluyen en su casa voluntariamente:

" $Y$ así es que, las que en sus casas cerradas $y$ ocupadas las mejoran, andando fuera dellas las destruyen. $Y$ las que, con andar por sus rincones, ganaran las voluntades $y$ edificaran las consciencias de sus maridos, visitando las calles corrompen los coraçones ajenos y enmollecen las almas de los que las veen, las que, por ser ellas muelles, se hizieron para la sombra y para el secreto de sus paredes» (León: 182).

"En vuestro natural recato hallará también el más escrupuloso qué admirar pues, en la voluntaria clausura que guardáis, se hallará cumplido en cuanto es posible lo que dize la Escritura Sagrada, que ni aún la fama de las donçellas ha de pasar de la vecindad. Las mugeres egipcias no usaban ningún calçado porque, como refiere Plutarco, no salían jamás de casa. Sulpicio Romano dexó a su muger porque la vio fuera, descubierto el rostro, y Publio Sempronio, filósofo, repudió la suya porque sin su licencia salió a ver los Juegos Olímpicos» (Rojo: 18v-19).

\section{Elección del marido}

En los tratados de Vives y de Rojo se aborda otra cuestión controvertida relativa al casamiento de la mujer: quién debe elegir al cónyuge. El valenciano defiende que la elección del marido es una tarea inalienable de los padres; solo ellos deben decidir quién se casará con su hija. Para justificar su parecer acude a un triple razonamiento. Por un lado, expone que la niña será demasiado joven en ese momento, por lo que podría dejarse llevar por motivaciones poco recomendables, pues no sabe lo suficiente de cómo se desarrolla la vida adulta. Por otro, Vives apela, una vez más, a la reputación de la familia de la joven. La honra de esta dependerá en gran medida de cómo los cónyuges afronten su vida en pareja. Así los padres son los mayores interesados en elegir al marido correcto para evitar posibles destemplanzas que afecten a la buena noticia de su casa:

"El que habla en casamiento debe pensar tan profundamente en ello como en cosa que le va la hacienda, la honra, y el descanso de su propia persona y carne que es su hija. No se debe tener en poco porque el casamiento es un nudo, que, ni se deja, ni se rompe. Sólo por mano de la muerte se ha de desatar y, como bien aconseja Publilio Siro: "Muchas veces se ha de pensar lo que no se hace sino una vez». En conclusión, sepan los padres que ellos ponen a sus hijas o en perpetua felicidad, casándolas bien, o en continua miseria, si las casan mal. En esto se debe pensar mucho mirar bien, consultar con unos y otros, antes que se determine, porque no es tan liviana cosa casarse que no sea lleno y cargado de mil enojos muy graves y de mil pesares enojosos» (Vives: 182-183).

Por otra parte, el tratadista juzga inadmisible que la doncella se case con un muchacho por el que experimente atracción, pues se extrae de ello que siente deseo sexual hacia él; las mujeres deben rehuir cualquier deseo lascivo, pues solo las deshonestas apetecen el placer de la carne. Puesto que el agrado por la dimensión erótica no estaba permitido a una de las dos partes de la pareja, puede extraerse otra máxima, y es que la actividad coital se producía cuando el marido la reclamaba. Se mostraba el sexo femenino como desprovisto de interés por la sexualidad o, en el peor de los casos, demonizado por tenerlo:

«También porque no está bien, ni es conveniente, que la doncella desee marido, o al menos, si le tuviere este deseo no debe darlo a sentir a nadie, porque en la doncella el tal deseo no carece de una cierta especie de deshonestidad" (Vives: 181).

Rojo coincide con Vives en tanto en cuanto considera que los progenitores deben de participar en la elección del esposo para su hija; no obstante manifiesta cierto progreso, pues defiende que los jóvenes deben conocerse previamente, pues debe garantizarse que se agraden física y emocionalmente, ay que de ello deriva la felicidad de la pareja:

"El que os he elegido entre tantos es, si no más rico que todos, tan noble como el primero de Castilla y del descanso y lustre que sabéis. La persona ya la visteis cuando, por mi orden, vuestra madre, que tiene el cielo, le envió aquí en nombre de criado suyo para que os viese y le viésedes, porque no fuera cordura que la primera vista viniera a ser para los dos, cuando el desagradarse alguno del otro que, en 
fin, es posible, fuera daño inevitable» (Rojo: 26v-27).

\section{Viudedad}

El último tema de esta comparación intertextual se corresponde con la última de las fases de la vida de las mujeres: la etapa de viudedad. El autor que más información aporta sobre este aspecto es Vives, quien explica cómo ha de tomarse la viuda la ausencia de su marido y cómo debe continuar su vida sin él. También Rojo se ocupa de ello en los diálogos séptimo y octavo. Ambos autores destacan la importancia de que la viuda no se abandone ni pierda las cualidades que tenía cuando estaba casada, sino que debe aceptar la voluntad de Dios y lograr en ella el consuelo para continuar:

"Ponga en su corazón la mujer desconsolada ser nuestras almas inmortales, y esta vida mortal ser carrera para la otra que es eterna, estábile y felicísima; la cual está aparejada y prometida a los que pura y limpiamente pasaron esta breve y transitoria, lo cual se alcanza no por bondad de aquél que muriendo mató nuestra muerte y desató los lazos de nuestra cautividad. Considere eso mismo que los que mueren nos van delante, y que nosotros seguiremos un poco después» (Vives: 356).

"Digo que, depuesto el dolor, os habíades de alegrar del bien que entendemos que goza por la dichosa disposiçión con que partió de esta vida y por la presunçión forçosa de la infinita misericordia que puso término a la suya en el tiempo más conveniente para su alma. Pues si esto no puede faltar, ¿cómo falta en vos la conformidad, y aún la alegría, de que haya cumplido la voluntad de nuestro señor en provecho de tan çierto de vuestro esposo? Y desatenta a las dos obligaciones, sentís vuestra soledad como si no quedase Dios obligado a ser fiel amparo y dulçe compañía de ella, supuesto que os quitó el mayor bien de los temporales, que fue un marido entendido, amable y amado con tanto extremo» (Rojo: 112v-114).

Juan Luis Vives profundiza más en los procesos de cambio de las viudas tras la pérdida de sus maridos. Después, lleva a examen dos de los comportamientos más comunes: la falta de dolor por la muerte del esposo y el exceso de llanto por el mismo motivo. Tras esto, propone la actitud supuestamente conveniente que debe mostrar una mujer que ha perdido a su pareja:

"Dos maneras de mujeres hallo yo en mi cuenta las cuales en llorar a los maridos yerran de una misma manera, aunque por diversos modos, es a saber, las que plañen demasiado, y las que nada o muy poco. Yo he visto en Flandes mujeres haber hecho tan poco sentimiento de la muerte de sus maridos como si apenas los hubieran conocido, lo cual es manifiesto señal de poco amor y de muy fría caridad, cosa por cierto tan cruel que dudo pueda haber otra en el mundo mayor ni más apartada de toda virtud y humanidad" (Vives: 351).

"Ahora hablando de las que lloran demasiado y no saben poner fin a sus llantos, digo que me parece que no yerran menos que las otras, porque, en recibiendo el golpe, hacen tanto sentimiento de la fresca herida, que todo confunden a gritos y llantos. Mésanse los cabellos, bátense los pechos, rascúñanse las mejillas, dan de cabezadas a la pared, échanse por tierra, hacen mil extremos, y alargan un año, y dos, y tres en llorar cada día, lo cual se usa mucho en Sicilia y en toda Grecia y Asia, y aún se solía usar mucho en Roma, hasta que el Senado proveyó en las leyes de las doce tablas y en sus decretos que no se hiciesen aquellos extremos, y hubiese algún orden y mesura en el llorar de los muertos» (Vives: 355).

"Llore, pues, la viuda a su marido con verdadero dolor, mas no dé voces, no se dé golpes con las manos, no se lastime ni se haga mal, duélase de manera que perezca (sic) haberse olvidado de su esposo y cordura, la cual nunca se enseña mejor que en el tiempo del destierro y las atribulaciones, conozcan las otras su dolor sin que ella lo quiera mostrar. En conclusión, deje los ademanes, y quédese con las lágrimas honestas y llenas de caridad» (Vives: 356).

\section{CONCLUSIONES}

A través de la comparación de las tres obras citadas es posible establecer una línea de evolución en la concepción de la enseñanza de la mujer desde el final de la Edad Media hasta las últimas décadas del XVII. En esta línea, La perfecta casada de Luis de León representa la mirada más recelosa hacia el desarrollo intelectual y social de la mujer. Así, es quien defiende la inferioridad física y espiritual de las mujeres con mayor vehemencia sirviéndose de los patrones heredados. De cerca lo sigue Juan Luis Vives con su tratado titulado Instrucción de la mujer cristiana, testigo de que las nuevas ideas humanistas apenas penetraron en el modelo de concepción de las mujeres ni favorecieron un cambio verdadero en su situación. De hecho, el texto del valenciano resulta tan crudo y castigador en varios de sus pasajes, que fue rápidamente censurado por Erasmo de Rotterdam (Capel Martínez, 2007: 89).

En cuanto al tercer testimonio que integra esta comparación, el Espejo de ilustres y perfectas señoras de Joseph Rojo, sirve para evaluar el grado de implantación en la conciencia social de finales del XVII de los cambios que llegaron con el Renacimiento y que fueron desarrollándose en las décadas posteriores. Más allá del contraste temporal, el análisis de esta obra es interesante por su carácter inédito y porque rescata la identidad y el pensamiento de un autor apenas conocido de la literatura española de finales del XVII. Frente a dos textos canónicos como son el de Vives o el Luis de León, este último aporta nuevos e interesantes puntos de vista sobre la educación femenina, en especial sobre todo lo que concierne a la vida conyugal, en una época en la que la literatura de instrucción gozaba de una menor popularidad.

Uno de los aspectos que da cuenta de la mayor modernidad del pensamiento de Rojo es la abierta defensa de la formación académica de las mujeres. Resulta especialmente curioso que sea el personaje masculino, don Enrique, quien lidere el discurso a favor de la intelectualidad femenina; un discurso que dedica una gran parte a atacar a todos aquellos teólogos, moralistas, etcétera que la condenan. Para ello aporta una larga lista de mujeres que brillaron en las artes y las ciencias a lo largo de toda la historia de la humanidad, pero además, inserta una enumeración de sabias que superaron a los varones en campos como la filosofía, la literatura o el gobierno. Igualmente innovadores resultan los pareceres de don Enrique cuando sostiene que la esposa y el marido deben haberse conocido antes de la boda, aunque 
esta haya sido acordada por los progenitores. Sostiene que tan solo cuando ambos cónyuges queden satisfechos con el exterior y el interior de la otra persona, el matrimonio podrá ser feliz y, por ende, rentable para los linajes de cada uno.

Con todo, el pensamiento reflejado a lo largo de los ocho diálogos de Rojo también presenta aspectos ligados a la tradición misógina en la que se amparan los textos de Vives y de Luis de León. El argumento más común en el discurso del dialoguista es la inferioridad biológica femenina, noción heredada del tratado De Animalia de Aristóteles, así como de la tradición cristiana del Génesis.

\section{FINANCIACIÓN}

Este trabajo se ha realizado durante el disfrute de un contrato predoctoral para la Formación del Profesorado Universitario (FPU17/02884) en el marco del proyecto "Dialogyca: Del manuscrito a la prensa periódica: estudios filológicos y editoriales del Diálogo hispánico en dos momentos" (DIALOMOM). № ref. PGC2018-095886-B-I00 (MCIU/AEI/FEDER) con sede en el Instituto Universitario Menéndez Pidal de la Universidad Complutense de Madrid.

\section{REFERENCIAS}

Aristóteles. 1999. Historia de los animales, trad. de José Vara Donada, Madrid: Akal.

Breitenstein, Renée-Claude. 2018. Célébrer les femmes entre éloge et défense: stratégies d'accréditation dans trois éloges collectifs de femmes imprimés au tournant des $X V$ et $\mathrm{XVI}{ }^{e}$ siècles, Exercices de rhétorique [en línea], 11, [20 de junio del 2018].

Capel Martínez, Rosa María. 2007. Mujer y educación en el Antiguo Régimen, Historia de la educación, 26: 85-110.

Cárceles Laborde, Concepción. 1993. Humanismo y educación en España (1450-1650), Pamplona: Ediciones Universidad de Navarra.

Charlton, Anna. 1999. Las mujeres y los animales, Teorema, 18 (3): 103-115.

Dialogyca BDDH. 2019. Consultado el 19/08/2019. www. dialogycabddh.es

Córdoba, Martín de. 1956. Jardín de nobles doncellas, ed. de Félix García, Madrid: Religión y Cultura.

Eiximenis, Francesc. 2007. Carro de las donas, ed. de Carmen Clausell Nácher, Madrid: Fundación Universitaria Española-Universidad Pontificia de Salamanca.

Horowitz, Maryanne Cline. 1976. Aristotle and Woman. Journal of History of Biology, 9 (2): 183-213.

León, Luis de. 2002. La perfecta casada, ed. de Javier San José Lera, Madrid: Espasa-Calpe (Planeta-DeAgostini).

Martí, Sacramento. 2004. "El oficio de mujer en las obras de Juan Luis Vives y Fray Luis de León”. En Lerner, Isaías; Nival, Roberto y Alonso, Alejandro (eds.), Actas del XIV Congreso de la Asociación Internacional de Hispanistas, vol. 2, 375-381. Nueva Jersey: Juan de la Cuesta-Hispanic Monographs.

Martín Casares, Aurelia. 2002. Las mujeres y la "Paz en la casa" en el discurso renacentista, Chronica Nova, 29: 217244.

Monsegú, Bernardo. 1961. Filosofía del humanismo de Juan Luis Vives, Santander: Editorial Cantabria.
Montalvo Mareca, Sergio. 2019. Rojo, José. Espejo de ilustres y perfectas señoras, en Dialogyca BDDH (Biblioteca Digital de Diálogo Hispánico), registro BDDH328. Puesto en red julio 2019. ISBN 978-8-4691-8286-4.

Montalvo Mareca, Sergio. 2018. Renacimiento y educación: Juan Luis Vives y la enseñanza de la mujer, Actas electrónicas del 8o Simposio Anual de Español, 8: 51-58.

Moreno Gallego, Valentín. 2006. La recepción hispana de Juan Luis Vives, Valencia: Generalitat valenciana.

Muguruza Roca, Isabel. 2010. Juan Luis Vives, el exemplum y la pedagogía femenina. En Gamba Corradine, Jimena y Bautista Pérez, Francisco (eds.), Estudios sobre la Edad Media, el Renacimiento y la temprana Modernidad, 681-689. Salamanca: Instituto Biblioteca Hispánica del Cilengua.

Nausia Pimoulier, Amaia. 2013. Talis mater, talis filia: las malas madres en los siglos XVI y XVII, Memoria y Civilización, 16: 27-54.

Ortega López, Margarita. 1988. La educación de la mujer en la Ilustración española, Revista de Educación, Extra 1: 303-325.

Rojo, Joseph. 1601-1700?. Espejo de ilustres y perfectas señoras [Manuscrito], Madrid: BNE, mss. 8802.

Vives, Juan Luis. 1995. Instrucción de la mujer cristiana, trad. de Juan Justiniano y ed. de Elizabeth Teresa Howe, Madrid: Fundación Universitaria Española-Universidad Pontificia de Salamanca. 